\title{
Estudo do comportamento corrosivo de compósitos metálicos em contato com biodiesel
}

\author{
Alfredo Luis Pereira Elias*, Beatriz Tavoni Longhim, Renata Favoretto, Éder Lopes Ortiz, Giovana da Silva \\ Padilha.
}

\section{Resumo}

O projeto traz um estudo do comportamento corrosivo de ligas metálicas comumente utilizadas em peças automotivas alumínio-silício e alumínio-cobre obtidas com diferentes formas de manufatura. As ligas Al-Si são obtidas por fundição e por metalurgia do pó, já a liga Al-Cu apenas por meio da fundição. Uma vez que a metalurgia do pó, diferentemente da fundição, propicia um produto mais próximo do modelo final, sem grandes perdas de material, porém podem apresentar grande porosidade em relação aos materiais fundidos, o que minimiza a resistência nesses materiais. Os meios corrosivos utilizados em contato com as ligas são biodiesel (B100), mistura biodiesel-diesel (B50) e blenda biodieseldiesel-etanol (B20D75E5). As análises são realizadas durante aproximadamente 6000 horas a temperatura ambiente e ausência de luz. Os produtos de corrosão são avaliados a partir da medida de perda de massa e de micrografias, após retirados dos meios corrosivos e submetidos às soluções de limpeza. As amostras de Al-Si fundidas mostram mudança mais significativa nas micrografias em comparação às ligas Al-Si via metalurgia do pó e Al-Cu fundidas. Já em relação aos meios corrosivos, todas as amostras apresentam perda de massa, porém as ligas que tiveram maiores perdas são as em contato com a blenda (B20D75E5), provavelmente devido a maior presença de água neste meio (confirmado por Karl Fischer). Os grupos funcionais presentes em cada meio corrosivo são analisados por FTIR-ATR.

Palavras-chave: ligas a base de alumínio, biocombustíveis e suas blendas, perda de massa.

\section{Introdução}

Devido à escassez dos recursos fósseis e a maior necessidade da obtenção de combustíveis biodegradáveis, o biodiesel é uma saída para as diversas necessidades atuais. No entanto, a corrosão em materiais automotivos é uma das preocupações relacionadas aos problemas de compatibilidade com os bioprodutos ${ }^{[1,2]}$. A investigação das características corrosivas do biodiesel são importantes para a durabilidade dos materiais que estiver em contato.

Sendo assim, o trabalho a seguir traz um estudo do comportamento de algumas ligas metálicas em contato com alguns combustíveis, mostrando que o biodiesel além de ser importante para a natureza não aumenta a perda de massa dos materiais, mesmo tendo um teor de água próximo ao B50 e menor que o B20D75E5 (compostos que possuem derivados de petróleo).

\section{Resultados e Discussão}

Figura 1. Análise dos grupos funcionais presentes no biodiesel e suas misturas.

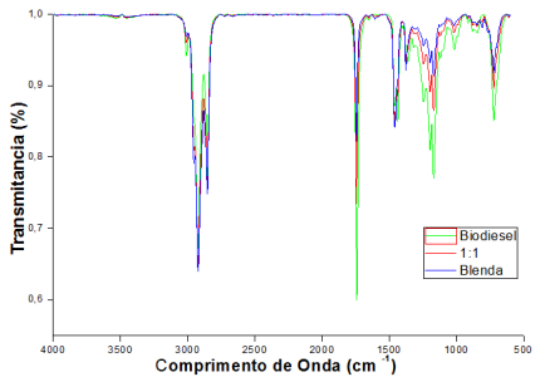

Tabela 1. Teor de água presente no biodiesel e suas misturas (por Karl Fischer)

\begin{tabular}{|lr|}
\hline B100 & $0,09 \%$ \\
B50 & $0,0415 \%$ \\
B20D75E5 & $0,17 \%$ \\
\hline
\end{tabular}

Tabela 2. Perda de massa das ligas em contato com os combustíveis.

\begin{tabular}{|ccrr|}
\hline \multicolumn{4}{c|}{ Perda de massa $(\mu \mathrm{g})$} \\
& Biodiesel & B50D50 & B20D75E5 \\
Al-Si Fundido & 7600 & 10900 & 12000 \\
Al-Cu Fundido & 3200 & 2800 & 3300 \\
Al-Si Metalurgia do pó & 2000 & 1600 & 4400 \\
\hline
\end{tabular}

Figura 2. Acompanhamento dos produtos de corrosão tempo 0 (imagens superiores) e 6000h (imagens inferiores).

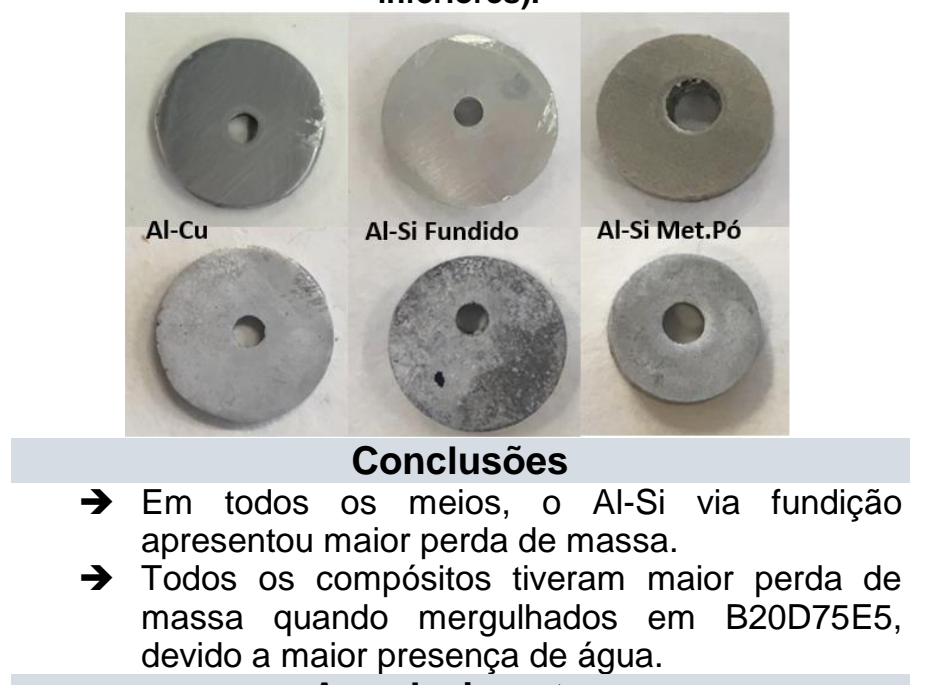

\section{Agradecimentos}

Gostaria de agradecer a minha orientadora Prof. Dra. Giovana da Silva Padilha, pela oportunidade e auxilio no meu projeto. Aos meus familiares e amigos pelo apoio em todos os momentos e ao CNPq pela concessão da bolsa de estudo.

\footnotetext{
${ }^{1}$ ASTM International. Standard practice for preparing, cleaning, and evaluating corrosion test specimens, ASTM G1-03, 2003.

${ }^{2}$ Chew k, ET AL. Corrosion of magnesium and aluminum in palm biodiesel: a comparative evaluation. Energy 57 (1), p. 478-483, 2013.
} 